\title{
Coral Reef Drag Coefficients-Surface Gravity Wave Enhancement
}

\author{
S. J. LENTZ AND J. H. CHURCHILL \\ Physical Oceanography, Woods Hole Oceanographic Institution, Woods Hole, Massachusetts \\ K. A. DAVIS \\ Civil and Environmental Engineering, University of California, Irvine, Irvine, California
}

(Manuscript received 7 November 2017, in final form 3 April 2018)

\begin{abstract}
A primary challenge in modeling flow over shallow coral reefs is accurately characterizing the bottom drag. Previous studies over continental shelves and sandy beaches suggest surface gravity waves should enhance the drag on the circulation over coral reefs. The influence of surface gravity waves on drag over four platform reefs in the Red Sea is examined using observations from 6-month deployments of current and pressure sensors burst sampling at $1 \mathrm{~Hz}$ for 4-5 min. Depth-average current fluctuations $U^{\prime}$ within each burst are dominated by wave orbital velocities $u_{w}$ that account for $80 \%-90 \%$ of the burst variance and have a magnitude of order $10 \mathrm{~cm} \mathrm{~s}^{-1}$, similar to the lower-frequency depth-average current $U_{\text {avg. Previous studies have shown that the cross-reef }}$ bottom stress balances the pressure gradient over these reefs. A bottom stress estimate that neglects the waves ( $\rho C_{d a} U_{\text {avg }} \mid U_{\text {avg }}$, where $\rho$ is water density and $C_{d a}$ is a drag coefficient) balances the observed pressure gradient when $u_{w}$ is smaller than $U_{\text {avg }}$ but underestimates the pressure gradient when $u_{w}$ is larger than $U_{\text {avg }}$ (by a factor of 3-5 when $u_{w}=2 U_{\text {avg }}$ ), indicating the neglected waves enhance the bottom stress. In contrast, a bottom stress estimate that includes the waves $\left.\left[\rho C_{d a}\left(U_{\text {avg }}+U^{\prime}\right)\left|U_{\text {avg }}+U^{\prime}\right|\right)\right]$ balances the observed pressure gradient independent of the relative size of $u_{w}$ and $U_{\text {avg }}$, indicating that this estimate accounts for the wave enhancement of the bottom stress. A parameterization proposed by Wright and Thompson provides a reasonable estimate of the total bottom stress (including the waves) given the burst-averaged current and the wave orbital velocity.
\end{abstract}

\section{Introduction}

A major challenge in modeling flow over coral reefs is parameterization of bottom drag (e.g., Rosman and Hench 2011; Lentz et al. 2017). Bottom drag is a dominant element of the dynamics over most shallow coral reefs (Monismith 2007; Hearn 2011; Lowe and Falter 2015). Surface gravity waves are often an important factor enhancing drag on lower-frequency currents in shallow water (e.g., Grant and Madsen 1986; Feddersen et al. 1998) and are likely to be important over many shallow coral reefs where surface gravity wave orbital velocities can be similar in magnitude to, or larger than, lower-frequency currents (Monismith et al. 2013; Lentz et al. 2017). While there have been numerous studies focusing on low-frequency currents (Roberts et al. 1975; Symonds et al. 1995; Kraines et al. 1998; Callaghan et al. 2006; Coronado et al. 2007; Jago et al. 2007; Hench et al. 2008; Lowe et al. 2009; Vetter et al. 2010; Taebi et al. 2011;

Corresponding author: S. J. Lentz, slentz@whoi.edu
Monismith et al. 2013) and on surface gravity wave evolution (Gerritsen 1980; Young 1989; Lugo-Fernandez et al. 1998a,b; Brander et al. 2004; Lowe et al. 2005; Péquignet et al. 2011; Harris and Vila-Concejo 2013; Monismith et al. 2015; Lentz et al. 2016b) over coral reefs, there have been almost no observational studies focusing on the potential enhancement of bottom drag by surface waves over shallow coral reefs (though see Hearn 1999). Failure to consider surface wave enhancement may result in overestimating hydrodynamic roughnesses and drag coefficients for coral reefs.

There are two basic models for enhancement of the drag by surface wave orbital velocities. One model assumes wave-induced stresses are confined to a thin wave boundary layer. In this case, large turbulent momentum fluxes in a very thin (order $\mathrm{cm}$ ) wave boundary layer result in an "apparent" enhanced hydrodynamic roughness acting on the lower-frequency flow (e.g., Grant and Madsen 1986). This increased bottom drag is due to the enhanced communication of the no-slip condition at the bottom to the low-frequency 
flow by the turbulence in the thin wave boundary layer. Formally, these wave-current boundary layer models assume that the wave-boundary layer thickness is $\delta_{w} \approx \kappa u_{*} / \omega$ ( $\kappa$ is von Kármán's constant, $u_{*}$ is the shear velocity, and $\omega$ is the wave frequency) and that $\delta_{w}$ is larger than the hydrodynamic (or physical) roughness (e.g., Grant and Madsen 1986). This makes application of these models to coral reefs problematic since both physical roughness and estimates of hydrodynamic roughness over coral reefs (e.g., Lentz et al. 2017) tend to be larger than the wave-boundary layer thickness.

An alternate, commonly used model of the average bottom stress with wave orbital velocities is

$$
\tau^{b}=\rho C_{d} \overline{\left(\mathbf{u}_{\mathrm{avg}}+\mathbf{u}^{\prime}\right)\left|\mathbf{u}_{\mathrm{avg}}+\mathbf{u}^{\prime}\right|}
$$

(see Feddersen et al. 2000 and references therein). Here $\rho$ is density, $C_{d}$ is a drag coefficient, $\mathbf{u}$ is a near-bottom current vector, $\mathbf{u}_{\text {avg }}$ and the overbar both indicate averages over a time scale that is long compared to the wave period, and $\mathbf{u}^{\prime}=\mathbf{u}-\mathbf{u}_{\text {avg }}$. Equation (1) is simple and straightforward to apply, but as noted by Trowbridge and Lentz (2018) the behavior of $C_{d}$ in (1) has not been explored theoretically. In the case of shallow coral reef flats with large roughness elements it seems plausible that the vertical scale of the wavedriven turbulence might depend on the roughness height and be much larger than $\delta_{w}$ (as defined above) [e.g., Mathisen and Madsen 1996; Dixen et al. 2008; see also section 5.1 in Trowbridge and Lentz (2018) for additional references]. Consequently the vertical scale of the wave-driven turbulence may be the same order as the boundary layer scale for low-frequency flow (i.e., the water depth) over shallow coral reefs. This is in sharp contrast to applications of the Grant-Madsen model to continental shelves where the bottom boundary layer associated with the low-frequency flow is three orders of magnitude thicker than the wave boundary layer ( $\sim 10 \mathrm{~m}$ vs $\sim 1 \mathrm{~cm})$. Equation (1) may be a sensible representation of the bottom stress in the case where the vertical scales of oscillatory and steady flow are similar.

The influence of wave orbital velocities on drag over several Red Sea coral reefs is examined using current and pressure measurements. The analyses indicate that surface gravity waves over shallow reef flats enhance the drag on the low-frequency reef currents and that the enhancement is consistent with (1).

\section{Coral reef sites and measurements}

Observations from four coral reefs on the eastern side of the Red Sea near Jeddah, Saudi Arabia, are examined (Fig. 1). QD2 and QD3 are two small platform reefs (Fig. 2) in the Qita Dukais reef system about $10 \mathrm{~km}$ offshore of the Saudi Arabian coast (Fig. 1). QD2 is about $200 \mathrm{~m}$ wide and $700 \mathrm{~m}$ long and is exposed to surface gravity waves from the Red Sea basin (Lentz et al. 2016a). QD3 is $250 \mathrm{~m}$ long and $100 \mathrm{~m}$ wide and is sheltered from the prevailing wave forcing (from the northwest) by QD2 and two other small reefs (note waves coming from northwest in Fig. 2). QD2 and QD3 are both about $1 \mathrm{~m}$ deep, relatively flat, and composed of pavement, coral rubble, small corals, and a few holes with sand (light-colored regions in Fig. 2) (Bernstein et al. 2016). Al Fahal is an elongated (9 $\mathrm{km}$ long and $0.5-1 \mathrm{~km}$ wide) coral reef aligned roughly north-south (Fig. 3a) and located about $12 \mathrm{~km}$ offshore of the Saudi Arabian coast (Fig. 1). The water depth increases across the reef from $0.6 \mathrm{~m}$ near its seaward edge to $3 \mathrm{~m}$ near the shoreward edge (Fig. 3c). The seaward portion of the reef is composed of pavement, coral rubble, small corals, and narrow channels (sites A2-A4 in Fig. 3b). The shoreward portion of the reef is sand (light regions between A4 and A5) with a broken line of shallow platform reefs running northsouth along the back edge of the reef (in vicinity of A6). Al Dagayig is another elongated reef $(1.4 \mathrm{~km}$ long and $300 \mathrm{~m}$ wide), located just south of Al Fahal (Fig. 1; Lentz et al. 2016a). Bathymetry and bottom composition are not available for Al Dagayig.

Instrument arrays of one or two Nortek Aquadopp current profilers bracketed by Sea-Bird SBE26 Seagauge pressure gauges were deployed across QD2, QD3, and Al Fahal (Figs. 2 and 3). Deployments were 6 months long, with three deployments at QD2 and one deployment at QD3 and Al Fahal. A current profiler was deployed for 1 year at roughly the middle of Al Dagayig.

In all deployments, the current profilers burstsampled at $1 \mathrm{~Hz}$ for 256 or $300 \mathrm{~s}$ every hour spanning the lower half of the water column with a vertical resolution of $2-5 \mathrm{~cm}$. The profilers were in pulse coherent mode, providing relatively accurate current measurements (error velocity of a few $\mathrm{mm} \mathrm{s}^{-1}$ ) [see appendix in Lentz et al. (2016a) for processing details]. Depth-average currents were estimated as a simple average of the current profiler bins that typically spanned the lower half of the water. Results were similar for depth averages estimated using an empirical orthogonal function analysis and assuming a log profile to extrapolate to the surface and bottom as in Lentz et al. (2016a). The pressure gauges collected mean pressures every $10 \mathrm{~min}$ and wave bursts at $2 \mathrm{~Hz}$ for $512 \mathrm{~s}$ every $4 \mathrm{~h}$. Estimated accuracy of sea level difference variations is a few $\mathrm{mm}$, based on laboratory tests, 


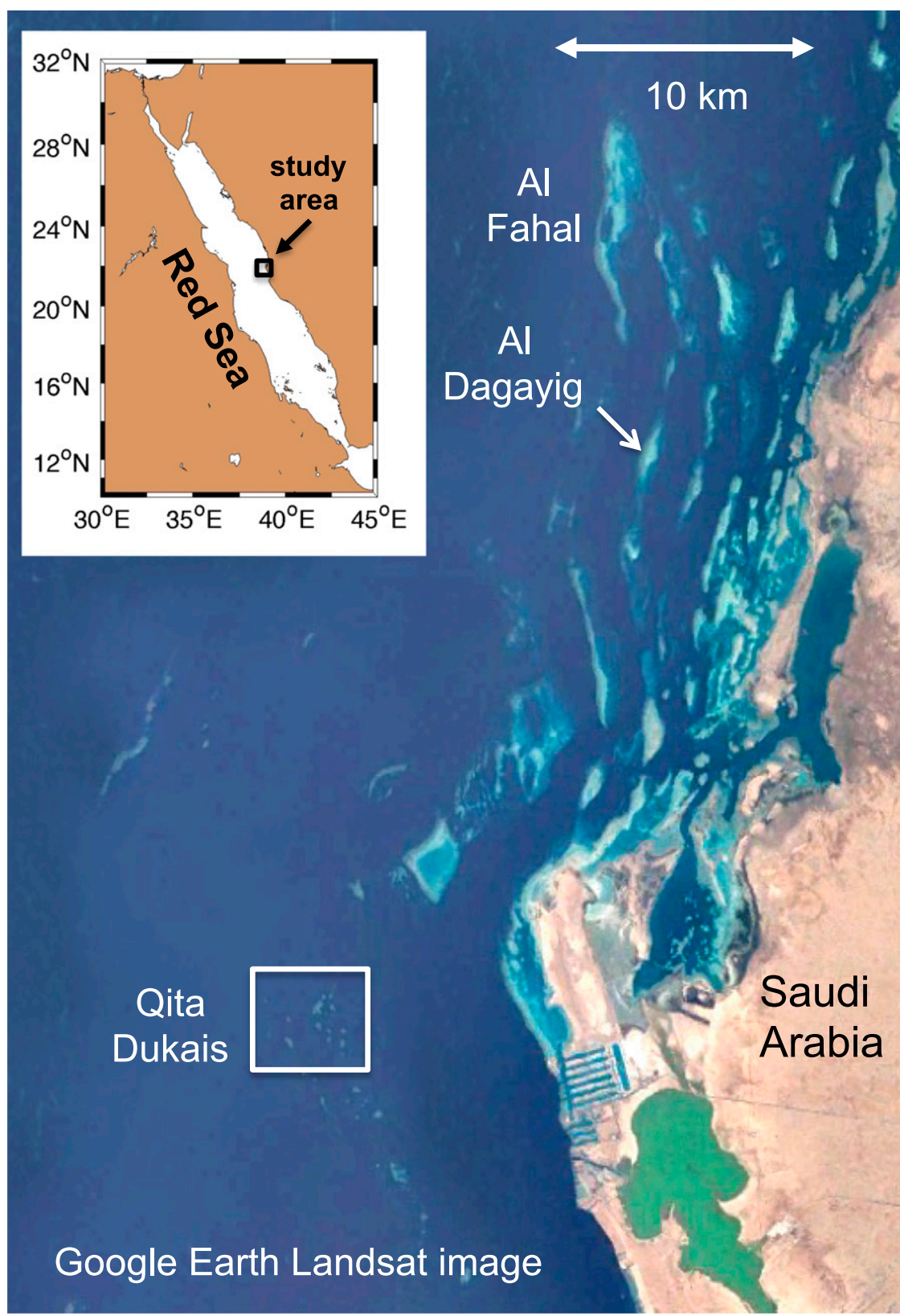

FIG. 1. Satellite image of study area showing Al Fahal and Al Dagayig reefs and the Qita Dukais reef system in the Red Sea off the coast of Saudi Arabia.

intercomparisons, and dynamical balances (e.g., Lentz et al. 1999, 2016a).

\section{Results}

a. Overview of surface gravity waves over Red Sea reef flats

Incident surface gravity waves from the Red Sea basin break at the seaward edge of the reefs resulting in setup that drives flows across the reef (cf. Figs. 4a and 4d; Lentz et al. 2016a). Onshore of the region of wave breaking, the surface gravity waves are generally much smaller than the incident waves (Fig. 4a) and often depth limited over the shallow reef flat; that is, $H_{s} \approx \gamma D$, where $H_{s}$ is significant wave height, $D$ is the water depth, and $\gamma \approx 0.5$ (Lentz et al. 2016b). Additionally, dissipation of wave energy over these reef flats, which depends on the water depth, can be substantial resulting in decay of the waves as they propagate across 

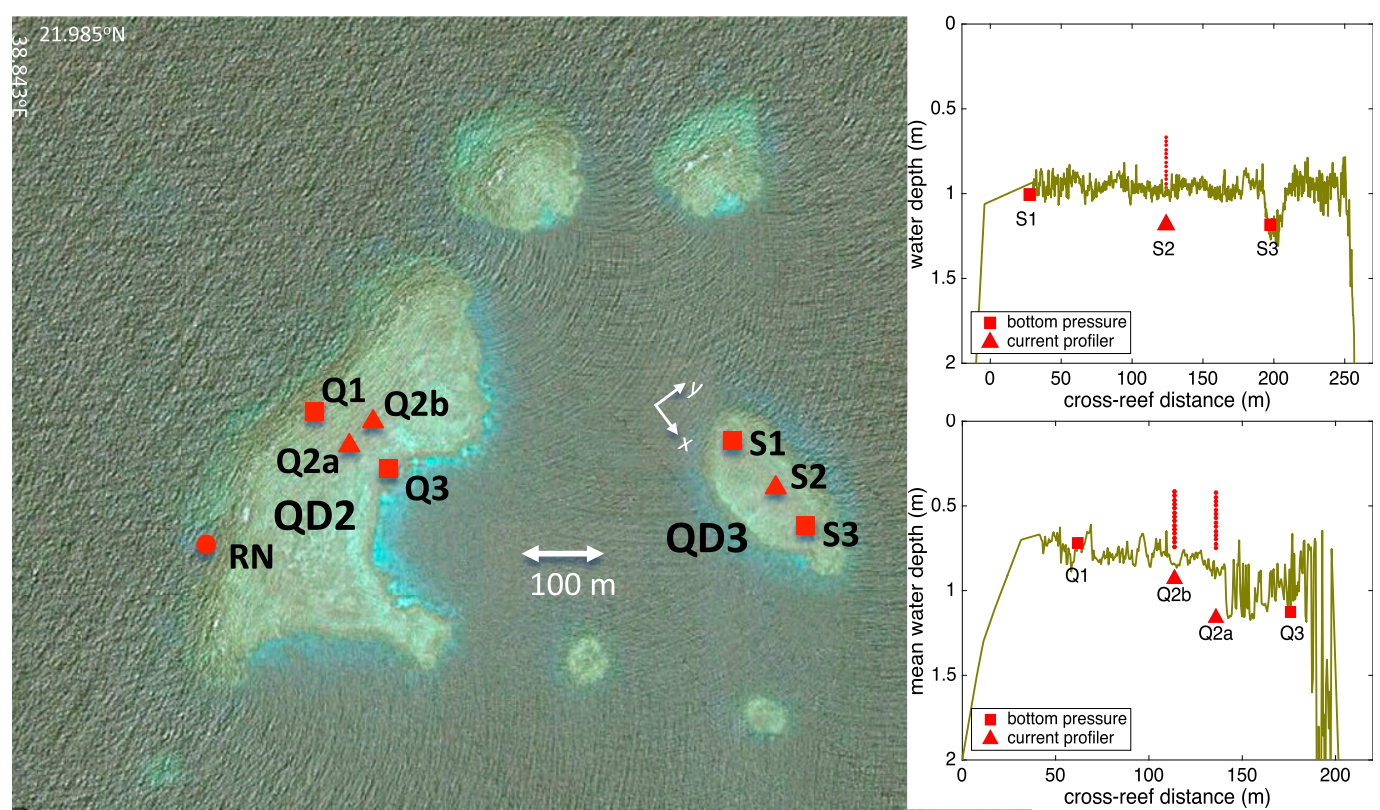

FIG. 2. (left) Satellite image (Apple Maps) of Red Sea platform reefs QD2 and QD3 in the Qita Dukais reef system (white box in Fig. 1) and pressure gauge (squares) and current profiler (triangles) locations. QD3 is sheltered from surface waves that typically propagate southeastward. (right) Bathymetry and instrument locations along the QD2 and QD3 transects are shown. The current profiler on QD2 was at Q2a for the first two deployments and at Q2b for the third deployment. Red bars above Q2a and Q2b indicate the range of current profiler bins.

the reef (Lentz et al. 2016b). As a result, wave heights (Fig. 4a, red trace) and wave orbital velocities (Fig. 4c) over the reef flat depend on the water depth, as well as the incident wave height. A clear example of the dependence of the reef flat wave characteristics on water depth is the 10-day period in January 2010 (between red dashed lines in Fig. 4). During this period, incident significant wave heights are relatively constant at $0.5 \mathrm{~m}$, but significant wave heights and orbital velocities over the reef flat decrease substantially in response to the reduction in water depth from 1.6 to $1.2 \mathrm{~m}$. Peak wave periods are typically $4-8 \mathrm{~s}$ (Lentz et al. 2016b), so these are shallow water waves over the reef flat where the water depth $(\sim 1 \mathrm{~m})$ is much smaller than the wavelength (i.e., $k D \ll 1$, where $k$ is the wavenumber).

To determine whether high-frequency current variability during burst samples is primarily due to surface gravity waves, the burst standard deviations are compared to estimates of the wave orbital velocity. The amplitude of wave orbital velocities $u_{w}$ are estimated by calculating spectra of the pressure observations during each burst, determining a significant wave height and peak period from the pressure spectra, and then using linear-wave theory and the burst-average water depth to compute $u_{w}$. Wave orbital velocities vary from 0 to $20 \mathrm{~cm} \mathrm{~s}^{-1}$ over the reef flats (Fig. 4c) and are similar in magnitude to the burst-average currents (Fig. 4d). Motions in the surface gravity wave band (periods $2-15 \mathrm{~s}$ ) account for $77 \%$ to $93 \%$ of the velocity variance in the 4-5-min bursts (Table 1). For sites with simultaneous burst pressure and current measurements, the estimates of wave orbital velocity from pressure $u_{w}$ are highly correlated with the current burst standard deviations $U_{\text {std }}^{\prime}$ with regression slopes approximately equal to the expected value of $U_{\text {std }}^{\prime}=u_{w} / \sqrt{2}$ and intercepts that are less than $1 \mathrm{~cm} \mathrm{~s}^{-1}$ (Table 1 ).

\section{b. Bottom stress estimates with and without wave orbital velocities}

Previous studies have shown that the pressure gradient and bottom stress terms dominate the depthaveraged, cross-reef momentum balance of these Red Sea reefs (Lentz et al. 2016a, 2017). The exception is QD3 where the cross-reef wind stress $\tau^{s x}$ contribution is significant because the reef is partially sheltered from the incident surface gravity waves. Thus, the cross-reef momentum balance is

$$
g D \frac{\partial \eta}{\partial x}=\frac{\tau^{s x}}{\rho}-\frac{\tau^{b x}}{\rho} .
$$

Here $\rho=1023 \mathrm{~kg} \mathrm{~m}^{-3}$ is an average water density, $g=$ $9.8 \mathrm{~m} \mathrm{~s}^{-2}, \eta$ is the sea level, and $x$ is the cross-reef 


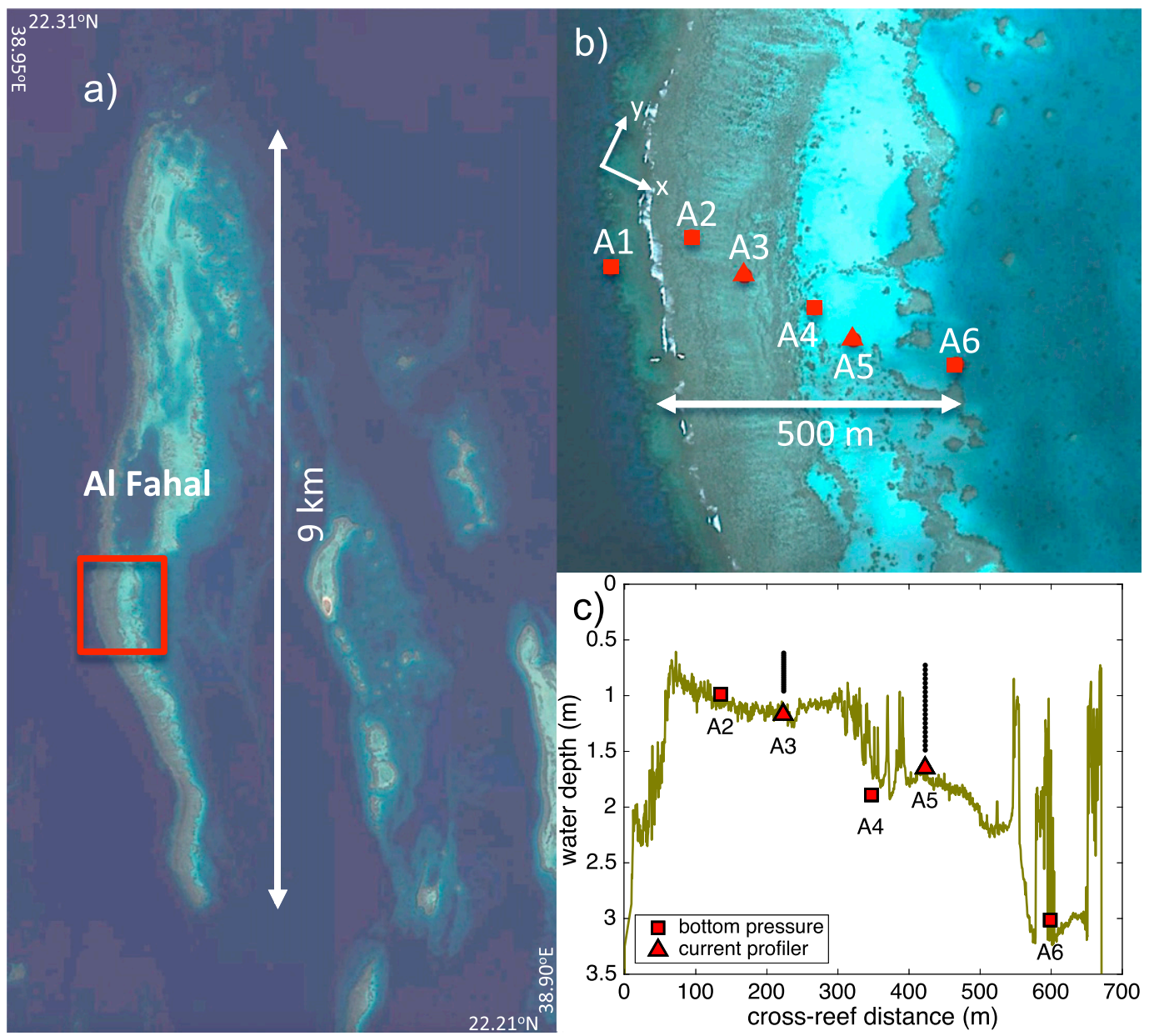

FIG. 3. (a) Satellite image (Google Earth) of Al Fahal reef in the Red Sea. (b) Enlarged view showing the pressure gauge (squares) and current profiler (triangles) locations. (c) Bathymetry and instrument locations across the reef. Black bars above A3 and A5 indicate the range of current profiler bins.

direction aligned with the pressure gauges. The bottom stress is estimated using either the burst average of the depth-average current $\mathbf{U}_{\text {avg }}$ [in contrast to (1) based on the near-bottom velocity],

$$
\tau_{\text {avg }}^{b x}=\rho C_{d a} U_{\text {avg }}\left|\mathbf{U}_{\text {avg }}\right|,
$$

or the total depth-average current, $\mathbf{U}=\mathbf{U}_{\mathrm{avg}}+\mathbf{U}^{\prime}$, including the burst fluctuations, and then averaging over the burst:

$\tau^{b x}=\rho C_{d a} \overline{U|\mathbf{U}|}=\rho C_{d a} \overline{\left(U_{\mathrm{avg}}+U^{\prime}\right)\left|\mathbf{U}_{\mathrm{avg}}+\mathbf{U}^{\prime}\right|}$.

Here the overbar indicates the burst average, $U$ is the cross-reef ( $x$ direction) and $V$ is the along-reef component of the depth-average current, and $\mathbf{U}=$ $(U, V)$. The following is a drag coefficient based on the depth-average current that depends on the water depth and the hydrodynamic roughness $z_{o}$ (Lentz et al. 2016a):

$$
C_{d a}=\kappa^{2}\left[\log \left(\frac{D}{z_{o}}\right)+(\Pi-1)\right]^{-2} .
$$

Here $\kappa=0.4$ is the von Kármán constant and $\Pi=0.2$ is Cole's wake strength (Nezu and Nakagawa 1993).

The applicability of (5) with the addition of waves is not clear because the wave orbital velocities have a different vertical structure than the essentially logarithmic profile used to derive (5). For the shallow-water waves $(k D \ll 1)$ over the reef flats the wave orbital velocities are nearly independent of depth. It is not clear how to generalize (5) to account for the vertical structure of the waves. Consequently, the analysis is also carried using currents at a fixed height above the bottom $(0.5 \mathrm{~m})$ rather than the depth-average flow, and a single optimal drag coefficient is chosen for each deployment 

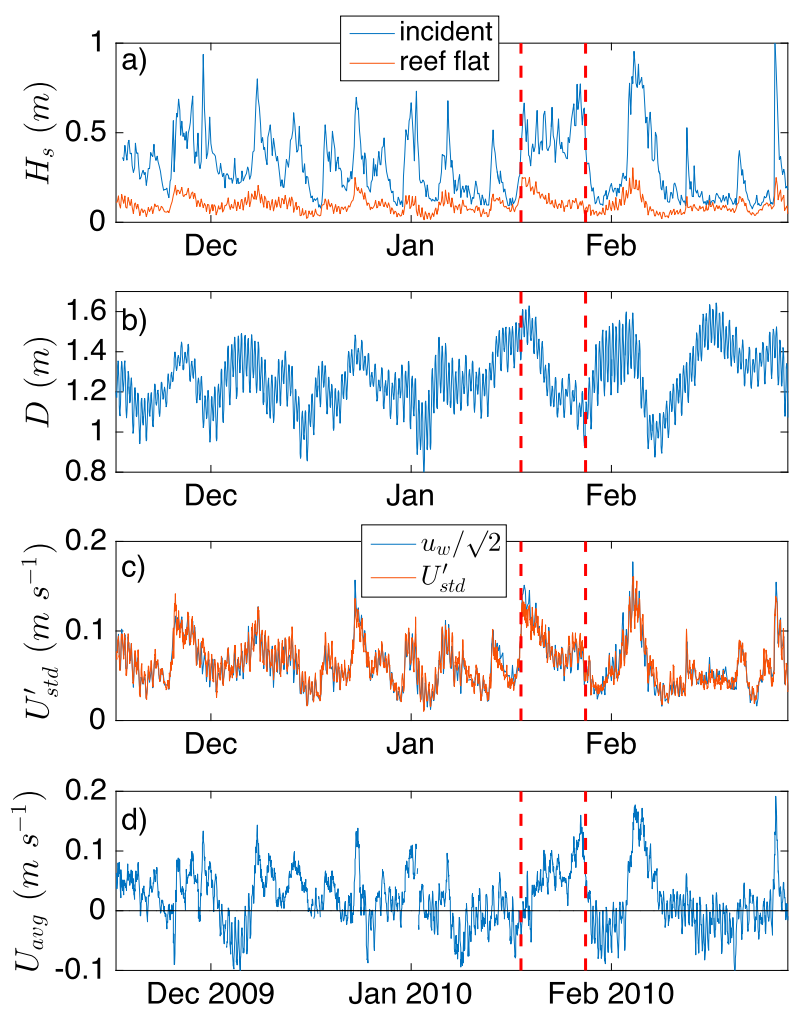

FIG. 4. Time series from QD2 first deployment of the (a) incident and reef flat significant wave heights at stations RN and Q1, respectively (Fig. 2), (b) water depth over the reef flat at Q2a, (c) wave orbital velocity and burst current standard deviation at Q2a, and (d) burst-average current at Q2a. The red dashed lines bracket a period when the incident significant wave height is relatively constant but the water depth decreases, highlighting the dependence of the reef flat wave height and orbital velocity on water depth variations. [Note in (c) the standard deviation of a sine wave with amplitude $\eta_{o}$ is $\eta_{o} / \sqrt{2}$.]

(appendix A) rather than (5). The key results are the same using either approach [cf. Fig. 6 (shown below) with Fig. A1 in appendix A]. The use of (5) also provides an extremely accurate estimate of the bottom stress based on comparison with the independently measured pressure gradient term (see below and Table 2), suggesting it is a reasonable estimate of the drag coefficient. Additionally, direct estimates of the drag coefficient from the ratio of the pressure gradient term and $\overline{\left(U_{\mathrm{avg}}+U^{\prime}\right)\left|\mathbf{U}_{\mathrm{avg}}+\mathbf{U}^{\prime}\right|}$ (as in Lentz et al. 2016a, 2017) exhibit the same dependence on water depth as (5), providing further justification for using (5). However, the broader relevance of this last result to other sites is not clear because the stronger dependence of $C_{d a}$ on water depth occurs when the water is shallow, which is also when the waves, and hence the wave influences, are small over the reef flat.

Determination of the bottom stress from (3) or (4) requires an estimate of $z_{o}$ to compute $C_{d a}$ from (5).
Following Lentz et al. (2016a) (see also Hearn 1999), the relationship between the pressure gradient, wind stress, and bottom stress is determined by assuming cross-reef transport is conserved across the reef and integrating (2) across the reef between two pressure gauges bracketing a current profiler using (3) or (4) with (5) to represent the bottom stress. The resulting cross-reef momentum balance may be written as follows (appendix B):

$$
g D_{C} \frac{\Delta \eta}{\Delta x}-\frac{\tau^{s x}}{\rho} W_{1}=-W_{3} C_{d a} U|\mathbf{U}|,
$$

where $D_{C}$ is a characteristic water depth, $W_{1}$ and $\mathrm{W}_{3}$ are order-one nondimensional weights that only depend on $D(x, t)$ and $z_{o}$, and $C_{d a}$ and $U$ are based on $D_{C}$. A single hydrodynamic roughness $z_{o}$ is found for each deployment that minimizes the root-mean-square (RMS) difference between the pressure gradient (or pressure gradient plus wind stress for QD3) and the bottom stress terms in (6), using either (3) or (4) with (5) to estimate the bottom stress term (Table 2). The currents are strongly polarized on all the reefs except QD3, so the flow measured at the current profiler traverses roughly the same section of the reef during each event. At QD3, where the flow is not polarized, evidence suggests that the drag coefficient ( or $z_{o}$ ) depends on flow direction. To reduce variability in estimates of the drag due to flow direction over QD3, analyses were limited to currents aligned with the principal axes $\left(210^{\circ} \mathrm{N}\right.$, most common flow direction) $\pm 20^{\circ}$, again using the projection of the current onto the line of the pressure gauges.

The bottom stress estimates $\tau_{\text {avg }}^{b x}$ based on the burstaverage current in (3) are highly correlated with the cross-reef pressure gradient term (Fig. 5a and Table 2). However, the regression slope between $\tau_{\text {avg }}^{b x}$ and the pressure gradient term increases as $\left|\mathbf{U}_{\text {std }}\right| /\left|\mathbf{U}_{\text {avg }}\right|$ (the ratio of the burst standard deviation $\left|\mathbf{U}_{\text {std }}\right|=\sqrt{U_{\text {std }}^{2}+V_{\text {std }}^{2}}$ to the burst-average velocity magnitude $\left.\left|\mathbf{U}_{\text {avg }}\right|\right)$ increases (Fig. 5a, colors and dashed lines). This indicates that the bottom stress is underestimated relative to the pressure gradient term for larger values of $\left|\mathbf{U}_{\text {std }}\right| /\left|\mathbf{U}_{\text {avg }}\right|$. In Figs. 5a and $5 \mathrm{~b}$ the same $z_{o}=3.5 \mathrm{~cm}$ is used, the optimal value for $\tau^{b x}$ (Table 2). For smaller values of $\left|\mathbf{U}_{\text {std }}\right| /\left|\mathbf{U}_{\text {avg }}\right|$ (dark blue circles) the regression slope approaches 1 , consistent with $z_{o}=3 \mathrm{~cm}$ being the correct hydrodynamic roughness in the absence of waves. These results are consistent with previous studies (e.g., Wright and Thompson 1983; Feddersen et al. 2000) indicating the enhancement of the stress due to surface waves should increase as $\left|\mathbf{U}_{\text {std }}\right| /\left|\mathbf{U}_{\text {avg }}\right|$ increases. Use of the optimal $z_{o}=4 \mathrm{~cm}$ for $\tau_{\text {avg }}^{b x}$ (Table 2) does not change Fig. 5a except to shift the cluster of points so they are more centered on the one-to-one line. 
TABLE 1. Median percentage of burst variance in the wave band (periods 2 to $15 \mathrm{~s}$ ) and the regression slope, intercept, and correlation from a linear regression analysis of the form $\left|U_{\text {std }}^{\prime}\right|=a u_{w} / \sqrt{2}+b$ between magnitude of burst standard deviations of the depth-average current and the wave orbital velocities estimated from pressure. (Note the standard deviation of a sine wave with amplitude $\eta_{o}$ is $\eta_{o} / \sqrt{2}$ ). The $95 \%$ confidence intervals for regression slope and intercept are also listed assuming an independence time scale of 1 day based on the autocorrelations.

\begin{tabular}{|c|c|c|c|c|}
\hline Site/deployment & $\begin{array}{l}\text { Median \% burst current } \\
\text { variance in wave band }\end{array}$ & Regression slope & Intercept $\left(\mathrm{cm} \mathrm{s}^{-1}\right)$ & Correlation \\
\hline QD2a & 86 & $1.12 \pm 0.12$ & $0.36 \pm 0.77$ & 0.95 \\
\hline QD2b & 77 & - & & - \\
\hline QD2c & 92 & $1.16 \pm 0.09$ & $0.48 \pm 0.94$ & 0.97 \\
\hline QD3 & 93 & - & & - \\
\hline Al Fahal A3 & 83 & $1.05 \pm 0.08$ & $0.43 \pm 0.60$ & 0.98 \\
\hline Al Fahal A5 & 82 & - & & - \\
\hline Al Dagayig & 77 & $1.34 \pm 0.08$ & $0.56 \pm 0.37$ & 0.92 \\
\hline
\end{tabular}

Bottom stress estimates $\tau^{b x}$ incorporating the wave orbital velocities in (4) are always slightly more correlated (the increase is generally not significant at the $95 \%$ confidence level) with the pressure gradient term than $\tau_{\text {avg }}^{b x}$ (Table 2). More importantly the relationship between $\tau^{b x}$ from (4) and the pressure gradient term is independent of $\left|\mathbf{U}_{\text {std }}\right| /\left|\mathbf{U}_{\text {avg }}\right|$ (Fig. 5b), indicating (4) accounts for the enhancement of the bottom stress by the wave orbital velocities. Using (4) rather than (3) slightly reduces the RMS difference between the bottom stress and pressure gradient term in all six deployments (Table 2). The RMS differences using (4) correspond to a sea level difference of $2-5 \mathrm{~mm}$, which is approximately the uncertainty of the pressure difference estimates.

The dependence of the bottom stress estimates on $\left|\mathbf{U}_{\text {std }}\right| /\left|\mathbf{U}_{\text {avg }}\right|$ is summarized for each site by calculating the linear regression between the bottom stress and pressure gradient term for 0.1 bins of $\left|\mathbf{U}_{\text {std }}\right| /\left|\mathbf{U}_{\text {avg }}\right|$ ranging from 0.2 to 3 (e.g., dashed lines in Fig. 5a). In each case the single value of $z_{o}$ that minimizes the RMS difference between the pressure gradient term and $\tau^{b x}$ (listed in Table 2) is used for both $\tau^{b x}\left[(4)\right.$ and (5)] and $\tau_{\text {avg }}^{b x}[(3)$ and (5)]. Using $\tau_{\text {avg }}^{b x}$ from (3), the regression slopes increase with increasing $\left|\mathbf{U}_{\text {std }}\right| /\left|\mathbf{U}_{\text {avg }}\right|$ from $\sim 1$ for $\left|\mathbf{U}_{\text {std }}\right| /\left|\mathbf{U}_{\text {avg }}\right|=0.5$ to between 3 and 4.5 for $\left|\mathbf{U}_{\text {std }}\right| /\left|\mathbf{U}_{\text {avg }}\right|=2$ (Fig. 6, circles). In contrast, using $\tau^{b x}$ from (4), which includes the wave orbital velocities, the regression slopes are $\sim 1$ and independent of $\left|\mathbf{U}_{\text {std }}\right| /\left|\mathbf{U}_{\text {avg }}\right|$ (Fig. 6, squares). Estimating bottom stress using currents at a fixed height above the bottom $(z=0.5 \mathrm{~m})$ and a constant drag coefficient rather than (5) yields the same dependencies (appendix A, Fig. A1). These results support the assumption that surface gravity waves enhance the bottom stress over shallow Red Sea coral reefs and that the enhancement is consistent with (4).

Failure to account for the surface gravity wave enhancement of the bottom stress results in overestimating the hydrodynamic roughness by $15 \%-70 \%$ for these reefs (Table 2). Using (5) this corresponds to overestimating the depth-average flow drag coefficient by $15 \%-60 \%$ when the water depth is $1 \mathrm{~m}$, or $30 \%-100 \%$ when the water depth is $0.5 \mathrm{~m}$.

\section{c. Dependence of bottom stress enhancement on orbital velocity direction}

The regression slopes for $\tau_{\text {avg }}^{b x}$ for QD2c and Fahal A3 (green and blue circles in Fig. 6) increase more rapidly for increasing $\left|\mathbf{U}_{\text {std }}\right| /\left|\mathbf{U}_{\text {avg }}\right|$ than for QD3 (red circles in Fig. 6). Numerous previous studies have shown that the relationship between $U_{\text {avg }}\left|\mathbf{U}_{\text {avg }}\right|$ and $\overline{\left(U_{\text {avg }}+U^{\prime}\right)\left|\mathbf{U}_{\text {avg }}+\mathbf{U}^{\prime}\right|}$ (or equivalently $\tau_{\text {avg }}^{b x}$ and $\tau^{b x}$ ) depends on characteristics of the wave field, such as whether the waves are isotropic or unidirectional and how they are aligned with the mean flow (Feddersen et al. 2000, and references therein). For example, for the case of isotropic high-frequency current variability $\left(V_{\text {std }} \approx U_{\text {std }}\right)$ Wright and Thompson (1983) showed that

TABLE 2. Correlations and RMS difference between the pressure gradient (with wind stress for QD3) and bottom stress terms and hydrodynamic roughness estimates $z_{o}$ that minimize the RMS difference. Bottom stress estimates are based on either the burst average flow $\tau_{\text {avg }}^{b x}$ or incorporating the current variability within each burst $\tau^{b x}$. RMS differences are converted to equivalent sea level heights, and $z_{o}$ estimates have been rounded to nearest $0.5 \mathrm{~cm}$.

\begin{tabular}{|c|c|c|c|c|c|c|}
\hline \multirow{2}{*}{$\begin{array}{c}\text { Site/ } \\
\text { deployment }\end{array}$} & \multicolumn{2}{|c|}{ Correlation } & \multicolumn{2}{|c|}{$\begin{array}{c}\text { RMS } \\
\text { difference }(\mathrm{cm})\end{array}$} & \multicolumn{2}{|c|}{$z_{o}(\mathrm{~cm})$} \\
\hline & $\tau^{b x}$ & $\tau_{\mathrm{avg}}^{b x}$ & $\tau^{b x}$ & $\tau_{\text {avg }}^{b x}$ & $\tau^{b x}$ & $\tau_{\text {avg }}^{b x}$ \\
\hline QD2a & 0.97 & 0.96 & 0.2 & 0.4 & 3.5 & 5.0 \\
\hline QD2b & 0.96 & 0.95 & 0.3 & 0.4 & 3.0 & 4.0 \\
\hline QD2c & 0.93 & 0.83 & 0.4 & 0.6 & 3.5 & 5.0 \\
\hline QD3 & 0.82 & 0.81 & 0.2 & 0.2 & 6.0 & 9.0 \\
\hline Al Fahal A3 & 0.95 & 0.90 & 0.5 & 0.8 & 6.0 & 7.0 \\
\hline Al Fahal A5 & 0.87 & 0.85 & 0.2 & 0.2 & 6.0 & 6.5 \\
\hline
\end{tabular}



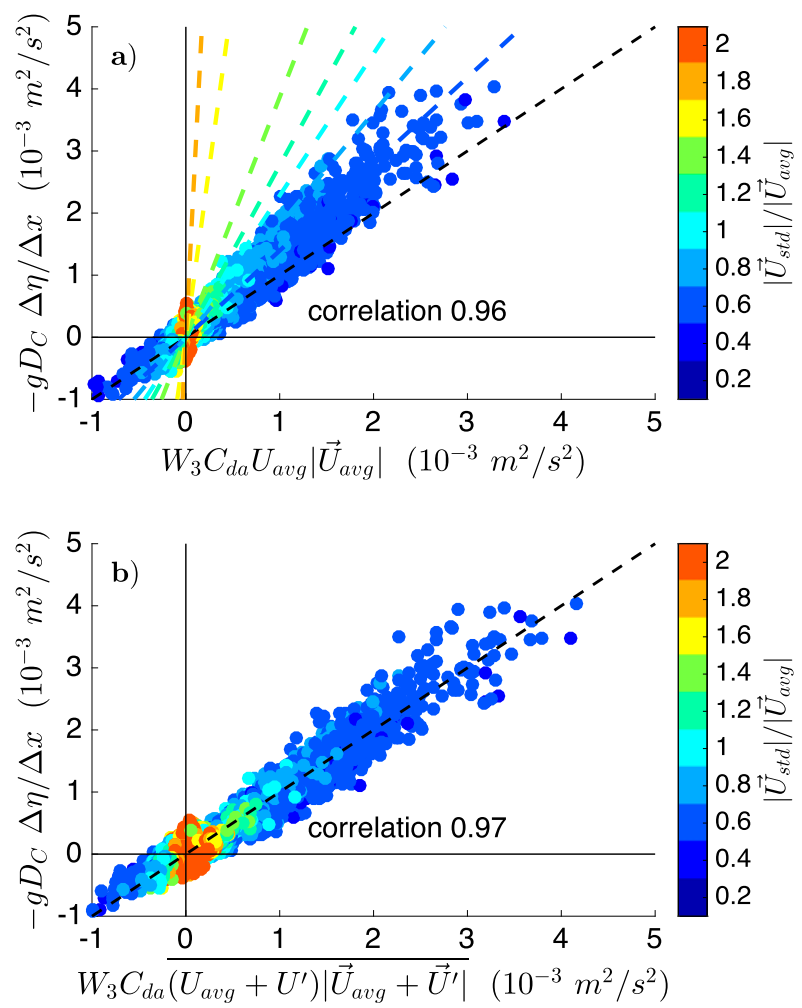

FIG. 5. The dependence of the pressure gradient term on the bottom stress based on (a) the 256-s burst-average current and (b) inclusion of the current variability within each 256-s burst (from the first deployment over QD2 reef). The optimal $z_{o}=3.5 \mathrm{~cm}$ for $\tau^{b x}$ is used in both panels. Colors of each hourly sample indicate the ratio of the magnitude of the burst standard deviation to the burst-average current magnitude. Colored dashed lines in (a) are regression slopes corresponding to 0.2 bins of $\left|\mathbf{U}_{\text {std }}\right| /\left|\mathbf{U}_{\text {avg }}\right|$ indicated by the color bar. Overall correlations between the bottom stress estimates and the pressure gradient term are also indicated (see Table 2).

$$
\begin{aligned}
\frac{\tau^{b x}}{\tau_{\mathrm{avg}}^{b x}} & =\frac{\overline{\left(U_{\mathrm{avg}}+U^{\prime}\right)\left|\mathbf{U}_{\mathrm{avg}}+\mathbf{U}^{\prime}\right|}}{U_{\mathrm{avg}}\left|U_{\mathrm{avg}}\right|} \\
& \approx \sqrt{1+\left(\alpha \frac{\left|U_{\mathrm{std}}\right|}{\left|U_{\mathrm{avg}}\right|}\right)^{2}},
\end{aligned}
$$

where $\alpha=1.33$. The estimates from the Red Sea reefs exhibit the same general dependence on $\left|\mathbf{U}_{\text {std }}\right| /\left|\mathbf{U}_{\text {avg }}\right|$ proposed by Wright and Thompson. The characteristics of the wave variability over each reef are examined to determine whether this accounts for the difference between QD3 and QD2c or Fahal A3 in Fig. 6.

The relative size of $U_{\text {std }}$ and $V_{\text {std }}$ over QD3 (the sheltered reef) and A5 on Al Fahal are different from the other sites (Fig. 7b) (remembering that $U_{\text {std }}$ and $V_{\text {std }}$ are standard deviations of burst current fluctuations

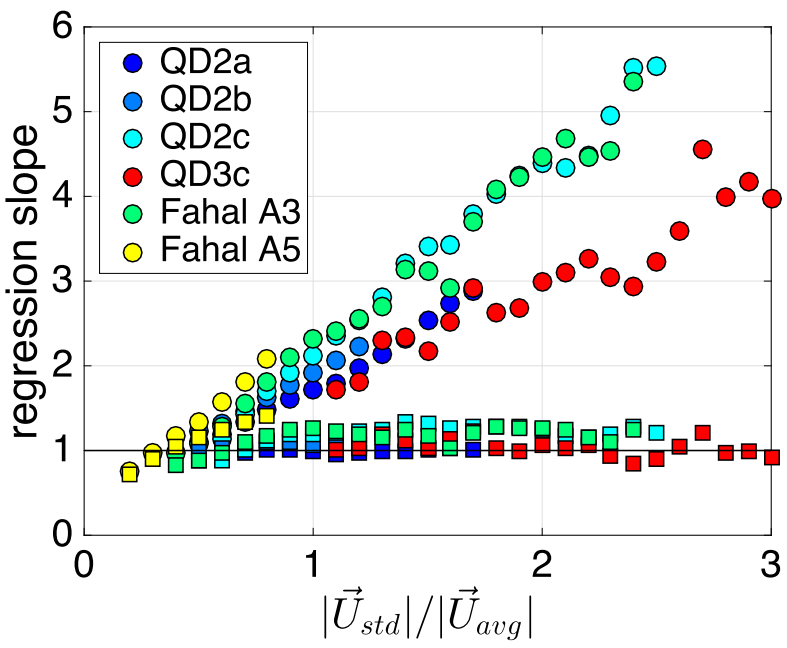

FIG. 6. Dependence of the regression slope between the pressure gradient and the bottom stress terms $\left(g D_{C} \Delta \eta / \Delta x=-a \tau^{b x} / \rho\right)$ on the ratio of the burst standard deviation of the current to the burst-average current magnitude. Symbol colors indicate different deployments and bottom stress estimates based on burst-average current $\tau_{\text {avg }}^{b x}[(3)]$ are indicated by circles, and bottom stress estimates that include burst variability $\tau^{b x}[(4)]$ are indicated by squares. QD3 estimates include the wind stress term.

parallel and perpendicular, respectively, to the pressure gauge lines at each site). Over QD3, $V_{\text {std }}$ are on average about $25 \%$ larger than $U_{\text {std }}$ (Fig. 7). At A5 over Al Fahal, $U_{\text {std }}$ and $V_{\text {std }}$ are about the same size (as assumed by Wright and Thompson 1983). At the other sites, $U_{\text {std }}$ is nearly twice the size of $V_{\text {std }}$ when $\left|\mathbf{U}_{\text {std }}\right| /\left|\mathbf{U}_{\text {avg }}\right|>1$. The difference between QD3 and most of the other sites is a combination of two factors: burst currents at QD3 are less polarized than at the other sites, and the orientation of the wave orbital velocities relative to the alignment of the pressure gauges is different. The dependence of $\overline{\left(U_{\mathrm{avg}}+U^{\prime}\right)\left|\mathbf{U}_{\mathrm{avg}}+\mathbf{U}^{\prime}\right|}$ divided by $U_{\text {avg }}\left|\mathbf{U}_{\text {avg }}\right|$ on $\left|\mathbf{U}_{\text {std }}\right| /\left|\mathbf{U}_{\text {avg }}\right|$ from the observations (Fig. 8, circles) are consistent with the relationships predicted by Monte Carlo simulations with different relative sizes of $U_{\text {std }}$ and $V_{\text {std }}$ (Fig. 8, dashed lines) characteristic of the different sites (from Fig. 7b). Specifically, the dependence

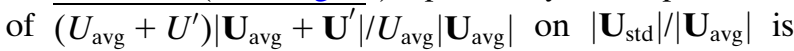
less steep for QD3 than for the other sites consistent with the difference seen in Fig. 6. The difference between QD3 and the other sites in Figs. 6 and 8 emphasizes the importance of the wave characteristics to the bottom stress enhancement.

\section{Summary}

Analysis of burst-sampled current profiles and pressure measurements collected over three shallow Red Sea coral reefs indicate that surface gravity wave orbital 

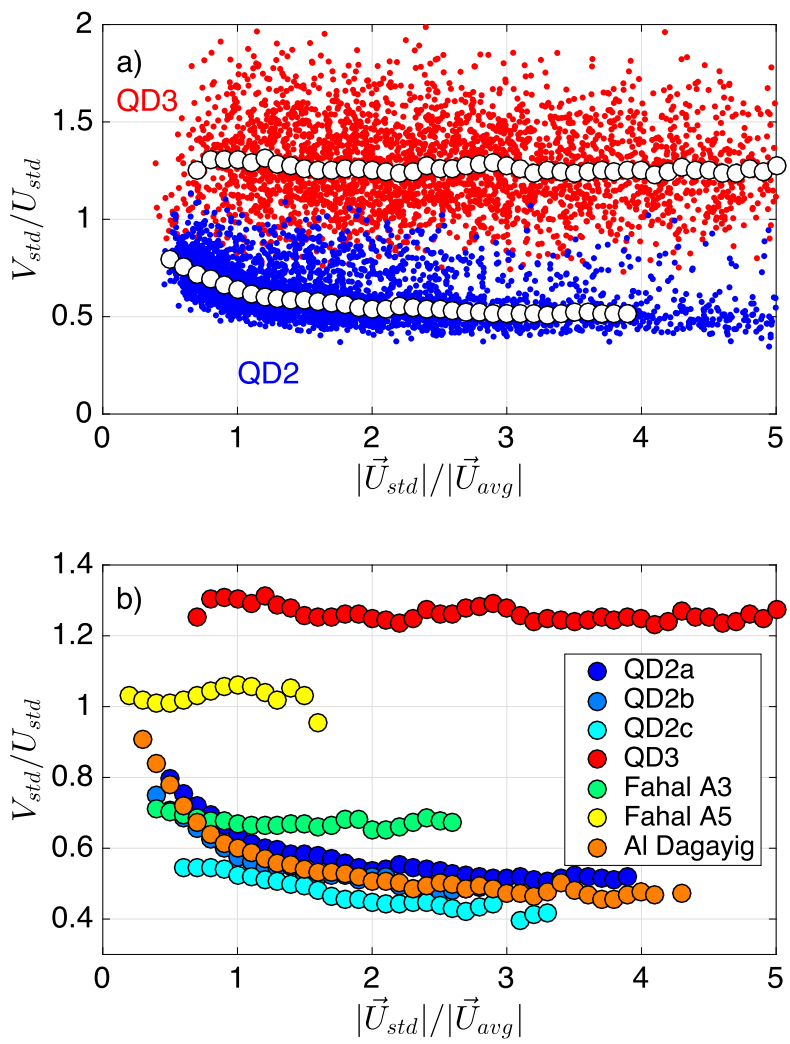

FIG. 7. The dependence of the ratio of the along- to cross-reef burst standard deviations on the ratio of the burst standard deviation magnitude to the burst-average magnitude for (a) hourly values from QD3 and QD2 and (b) bin-averages for each deployment [also shown as white circles for QD2 and QD3 in (a)].

velocities (ranging from 2 to $30 \mathrm{~cm} \mathrm{~s}^{-1}$ ) enhance the drag on the lower-frequency (hourly) flow (magnitude ranging from 0 to $30 \mathrm{~cm} \mathrm{~s}^{-1}$ ) consistent with (4) (Figs. 5 and $6)$. This enhancement should occur over any reef where the roughness elements are large compared to a characteristic wave boundary layer scale. This study examined reef flats onshore of the region of wave breaking, and consequently waves were relatively small. The wave enhancement of drag is likely to be much larger where wave orbital velocities are large, for example, in the region of wave breaking and on the fore-reef prior to wave breaking. Over these Red Sea reef flats the lowfrequency current is driven primarily by surface gravity wave breaking (e.g., Lentz et al. 2016a), and consequently the low-frequency currents are strongly correlated with surface gravity wave orbital velocities. It would be interesting to do a similar study over reefs dominated by tidal forcing (Lowe and Falter 2015) but still influenced by surface waves.

The results of this study emphasize the need to include surface gravity wave effects in biochemical and physical models of coral reefs. Surface gravity wave orbital

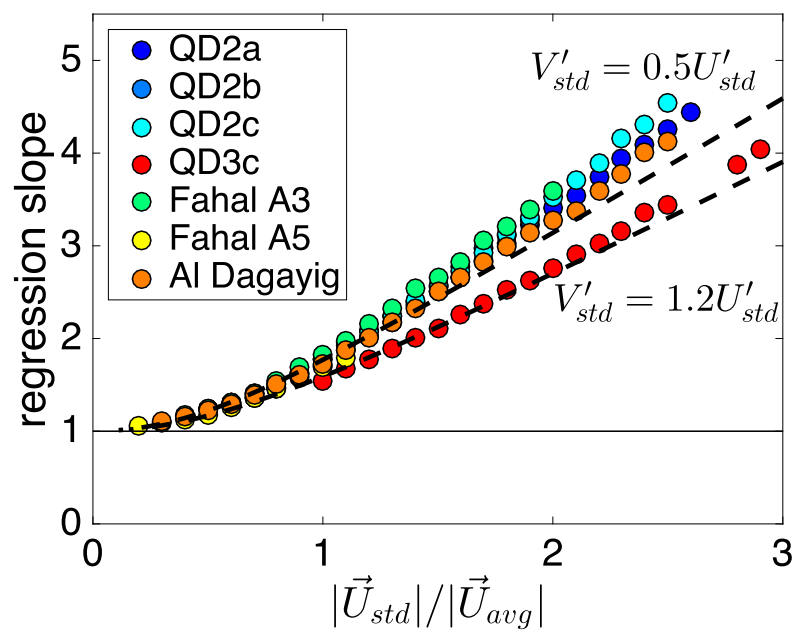

FIG. 8. Dependence of the regression slope between $\overline{\left(U_{\text {avg }}+U^{\prime}\right)\left|\mathbf{U}_{\text {avg }}+\mathbf{U}^{\prime}\right|}$ and $U_{\text {avg }}\left|\mathbf{U}_{\text {avg }}\right|$ on the ratio of the burst standard deviation of the current to the burst-average current magnitude. Colors indicate different deployments. Dashed lines are Monte Carlo simulations assuming normally distributed burst velocity fluctuations with the along-reef standard deviation $V_{\text {std }}^{\prime}$ equal to either half (upper dashed line) or 1.2 times (lower dashed line) the cross-reef standard deviation $U_{\text {std }}^{\prime}$. The two choices are motivated by the observed standard deviations (Fig. 7b).

velocities vary substantially across coral reefs, not only because of wave breaking but also because the large drag results in substantial dissipation of the waves over relatively short scales (Lowe et al. 2005; Lentz et al. 2016b). This implies that the surface gravity wave enhancement of drag will vary across reefs, and consequently accurate models of low-frequency flow over coral reefs require accurately modeling the evolution of the surface gravity waves across reefs.

Finally, surface gravity wave enhancement must be considered in observational studies estimating hydrodynamic roughnesses or drag coefficients. For the reef flats examined in this study where surface gravity waves are relatively small failure to consider surface wave enhancement of the drag resulted in overestimating hydrodynamic roughnesses (Table 2) and drag coefficients by $15 \%-70 \%$.

Acknowledgments. The authors thank Dr. Yasser Abualnaja, Dr. Abdulaziz Al-Suwailem, Haitham Aljahdali, Mohsen Aljahdali, Ramzi Aljahdali, Wael Almoazen, Captain Evangelos G. Aravantinos, Yasser Kattan, the whaler crew from King Abdullah University of Sciences and Technology (KAUST), and C. Marquette of Woods Hole Oceanographic Institution (WHOI) for providing logistical and field support. Suggestions from an anonymous reviewer substantially improved the manuscript. The Red Sea field program was supported by Awards USA 00002 and KSA 00011 made by KAUST. Data are available from corresponding author (slentz@whoi.edu) upon request, 
subject to approval from KAUST. S. Lentz was supported for the analysis by NSF Award OCE-1558343.

\section{APPENDIX A}

\section{Using Bottom Stress Estimated from Currents at a Fixed Height.}

The analyses in section $3 \mathrm{~b}$ were redone using bottom stress estimates based on the currents at a fixed height above the bottom [(1)] rather than the depth-average current so that there is a fixed drag coefficient that does not depend on the water depth. In this case,

$$
\begin{aligned}
\tau_{\text {avg }}^{b x} & =\rho C_{d} \bar{u}_{b}\left|\bar{u}_{b}\right| \quad \text { and } \\
\tau^{b x} & =\rho C_{d}\left(\bar{u}_{b}+u_{b}^{\prime}\right)\left|\bar{u}_{b}+u_{b}^{\prime}\right|,
\end{aligned}
$$

where $u_{b}=u(z=0.5 \mathrm{~m})$ and $C_{d}$ is the drag coefficient for that height. The height $z=0.5 \mathrm{~m}$ was chosen so that the same height could be used at all the sites. Defining the vertical location of the bottom is somewhat ambiguous because of the large variations in roughness over these coral reefs (Lentz et al. 2016a). As in appendix B, we divide (2) by the water depth $D$ and integrate in $x$ between the two pressure gauges. However, in the present case we assume the bottom stress does not vary between the pressure gauges because we cannot use continuity to determine the variations in $u_{b}$. The bottom stress is given by one of the two forms in (A1), and the wind stress is only included for QD3. Similar to the analysis used to generate Fig. 6, the drag coefficients' dependence on $\left|\mathbf{U}_{\text {std }}\right| /\left|\mathbf{U}_{\text {avg }}\right|$ for each site/deployment is determined by a linear regression analysis between the bottom stress and pressure gradient terms (plus wind stress at QD3) in (6) for 0.1 bins of $\left|\mathbf{U}_{\text {std }}\right| /\left|\mathbf{U}_{\text {avg }}\right|$ ranging from 0.2 to 3 . The two estimates of the bottom stress given by (A1) exhibit the same dependence on $\left|\mathbf{U}_{\text {std }}\right| /\left|\mathbf{U}_{\text {avg }}\right|$ in Fig. A1 as in Fig. 6.

\section{APPENDIX B}

\section{Integration of the Cross-Reef Momentum Balance}

Following Lentz et al. (2016a), to relate the pressure difference between two pressure gauges at $x_{1}$ and $x_{2}$ to the bottom stress from a single current profiler, (2) is divided by $D$ and then integrated from $x_{1}$ to $x_{2}$ assuming the cross-reef component of the transport $q^{x}$ is conserved (independent of $x$ ). This yields

$$
q^{x}|\mathbf{q}| \int_{x_{1}}^{x_{2}} C_{d a} D^{-3} d x=-g \Delta \eta+\frac{\tau^{s x}}{\rho} \int_{x_{1}}^{x_{2}} D^{-1} d x
$$

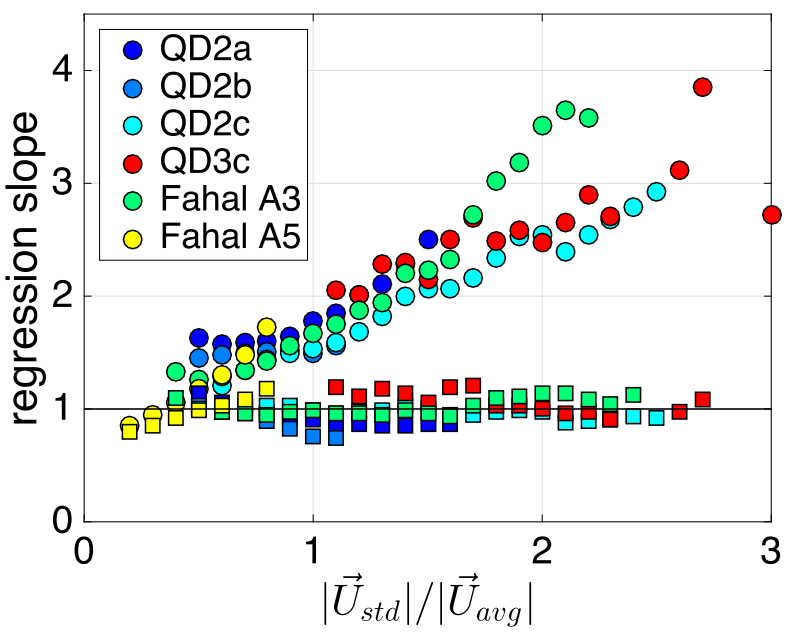

FIG. A1. Dependence of the regression slope between the pressure gradient and the bottom stress terms from currents at a fixed height $\left(g \Delta \eta=-a\left(\tau^{b x} / \rho\right) \int D^{-1} d x\right)$ on the ratio of the burst standard deviation of the current to the burst average current magnitude. Symbol colors indicate different deployments and bottom stress estimates [(A1)] based on burst average current $\tau_{\text {avg }}^{b x}$ (circles) and bottom stress estimates that include burst variability $\tau^{b x}$ (squares). QD3 estimates include the wind stress term. The same dependence is seen for bottom stresses based on currents at a fixed height as for bottom stresses based on depth-average currents (Fig. 6).

where the wind stress is assumed to be uniform between $x_{1}$ and $x_{2}$. It is convenient to use (5) to define a time dependent characteristic water depth $D_{C}$ such that

$$
\begin{aligned}
C_{d a}\left(D_{C}, z_{o}\right) & =\kappa^{2}\left[\log \left(\frac{D_{C}}{z_{o}}\right)+(\Pi-1)\right]^{-2} \\
& =\int_{x_{1}}^{x} C_{d a} D^{-3} d x / \int_{x_{1}}^{x} D^{-3} d x
\end{aligned}
$$

Solving for $D_{C}$,

$D_{C}=z_{o} \exp \left[(1-\Pi)+\kappa\left(\int_{x_{1}}^{x} C_{d a} D^{-3} d x / \int_{x_{1}}^{x} D^{-3} d x\right)^{-1 / 2}\right]$.

Using (B2) in (B1), multiplying by $D_{C}$, and dividing by $\Delta x=x_{2}-x_{1}$

$$
\begin{aligned}
W_{3} C_{d a} U|\mathbf{U}| & =-g D_{C} \frac{\Delta \eta}{\Delta x}+\frac{\tau^{s x}}{\rho} W_{1} \\
\text { where } W_{3} & =\frac{1}{\Delta x} \int_{x_{1}}^{x_{2}}\left(\frac{D_{C}}{D}\right)^{3} d x \quad \text { and } \\
W_{1} & =\frac{1}{\Delta x} \int_{x_{1}}^{x_{2}} \frac{D_{C}}{D} d x
\end{aligned}
$$


are order-one nondimensional weights that only depend on water depth and $z_{o}$, and $\mathbf{U}$ is the depth-averaged velocity corresponding to $D_{C}$ (which is independent of $x$ ).

\section{REFERENCES}

Bernstein, W. N., K. A. Hughen, C. Langdon, D. C. McCorkle, and S. Lentz, 2016: Environmental controls on daytime net community calcification on a Red Sea reef flat. Coral Reefs, $\mathbf{3 5}$, 697-711, https://doi.org/10.1007/s00338-015-1396-6.

Brander, R. W., P. S. Kench, and D. Hart, 2004: Spatial and temporal variations in wave characteristics across a reef platform, Warraber Island, Torres Strait, Australia. Mar. Geol., 207, 169-184, https://doi.org/10.1016/j.margeo.2004.03.014.

Callaghan, D. P., P. Nielsen, N. Cartwright, M. R. Gourlay, and T. E. Baldock, 2006: Atoll lagoon flushing forced by waves. Coastal Eng., 53, 691-704, https://doi.org/10.1016/ j.coastaleng.2006.02.006.

Coronado, C., J. Candela, R. Iglesias-Prieto, J. Sheinbaum, M. Lopez, and F. J. Ocampo-Torres, 2007: On the circulation in the Puerto Morelos fringing reef lagoon. Coral Reefs, 26, 149-163, https:// doi.org/10.1007/s00338-006-0175-9.

Dixen, M., F. Hatipoglu, B. Mutlu Sumer, and J. Fredsoe, 2008: Wave boundary layer over a stone-covered bed. Coastal Eng., 55, 1-20, https://doi.org/10.1016/j.coastaleng.2007.06.005.

Feddersen, F., R. T. Guza, S. Elgar, and T. H. C. Herbers, 1998: Alongshore momentum balances in the nearshore. J. Geophys. Res., 103, 15 667-15 676, https://doi.org/10.1029/98JC01270.

,,$-- \ldots$, and -2000 : Velocity moments in alongshore bottom stress parameterizations. J. Geophys. Res., 105, 86738686, https://doi.org/10.1029/2000JC900022.

Gerritsen, F., 1980: Wave attenuation and wave set-up on a coastal reef. Proc. 17th Int. Conf. on Coastal Engineering, Reston, VA, American Society of Civil Engineering, 444-461.

Grant, W. D., and O. S. Madsen, 1986: The continental-shelf bottom boundary layer. Annu. Rev. Fluid Mech., 18, 265-305, https://doi.org/10.1146/annurev.fl.18.010186.001405.

Harris, D. L., and A. Vila-Concejo, 2013: Wave transformation on a coral reef rubble platform. Proc. Int. Coastal Symp., Plymouth, United Kingdom, Plymouth University, 506-510, https://doi.org/10.2112/SI65-086.1.

Hearn, C. J., 1999: Wave-breaking hydrodynamics within coral reef systems and the effect of changing relative sea level. J. Geophys. Res., 104, $30007-30019$, https://doi.org/10.1029/ 1999JC900262.

_ 2011: Perspectives in coral reef hydrodynamics. Coral Reefs, 30, 1-9, https://doi.org/10.1007/s00338-011-0752-4.

Hench, J. L., J. J. Leichter, and S. G. Monismith, 2008: Episodic circulation and exchange in a wave-driven coral reef and lagoon system. Limnol. Oceanogr., 53, 2681-2694, https:// doi.org/10.4319/1o.2008.53.6.2681.

Jago, O. K., P. S. Kench, and R. W. Brander, 2007: Field observations of wave-driven water-level gradients across a coral reef flat.J. Geophys. Res., 112, C06027, https://doi.org/10.1029/ 2006JC003740.

Kraines, S. B., T. Yanagi, M. Isobi, and H. Komiyama, 1998: Windwave driven circulations on the coral reef at Bora Bay, Miyako Island. Coral Reefs, 17, 133-143, https://doi.org/10.1007/ s003380050107.

Lentz, S. J., R. T. Guza, S. Elgar, F. Feddersen, and T. H. C. Herbers, 1999: Momentum balances on the North Carolina inner shelf. J. Geophys. Res., 104, 18205-18226, https://doi.org/ 10.1029/1999JC900101.

J. H. Churchill, K. A. Davis, J. T. Farrar, J. Pineda, and V. Starczak, 2016a: The characteristics and dynamics of wavedriven flow across a platform coral reef in the Red Sea. J. Geophys. Res. Oceans, 121, 1360-1376, https://doi.org/ 10.1002/2015JC011141.

,,--- , and,$- 2016 \mathrm{~b}$ : Surface gravity wave transformation across a platform coral reef in the Red Sea. J. Geophys. Res. Oceans, 121, 693-705, https://doi.org/10.1002/ 2015JC011142.

- , K. A. Davis, J. H. Churchill, and T. M. DeCarlo, 2017: Coral reef drag coefficients-Water depth dependence. J. Phys. Oceanogr., 47, 1061-1075, https://doi.org/10.1175/ JPO-D-16-0248.1.

Lowe, R. J., and J. L. Falter, 2015: Oceanic forcing of coral reefs. Annu. Rev. Mar. Sci., 7, 43-66, https://doi.org/10.1146/ annurev-marine-010814-015834.

,-- M. D. Bandet, G. Pawlak, and M. J. Atkinson, 2005: Spectral wave dissipation over a barrier reef. J. Geophys. Res., 110, C04001, https://doi.org/10.1029/2004JC002711.

$\longrightarrow,-$, S. G. Monismith, and M. J. Atkinson, 2009: Wave-driven circulation of a coastal reef-lagoon system. J. Phys. Oceanogr., 39, 873-893, https://doi.org/10.1175/2008JPO3958.1.

Lugo-Fernandez, A., H. H. Roberts, and J. N. Suhayda, 1998a: Wave transformations across a Caribbean fringing-barrier coral reef. Cont. Shelf Res., 18, 1099-1124, https://doi.org/ 10.1016/S0278-4343(97)00020-4.

—_ — _ and W. J. Wiseman, 1998b: Tide effects on wave attenuation and wave setup on a Caribbean coral reef. Estuarine Coastal Shelf Sci., 47, 385-393, https://doi.org/ 10.1006/ecss.1998.0365.

Mathisen, P. P., and O. S. Madsen, 1996: Waves and currents over a fixed rippled bed: 2. Bottom and apparent roughness experienced by currents in the presence of waves. J. Geophys. Res., 101, 16543-16 550, https://doi.org/10.1029/ 96JC00955.

Monismith, S. G., 2007: Hydrodynamics of coral reefs. Annu. Rev. Fluid Mech., 39, 37-55, https://doi.org/10.1146/ annurev.fluid.38.050304.092125.

_ L. M. M. Herdman, S. Ahmerkamp, and J. L. Hench, 2013: Wave transformation and wave-driven flow across a steep coral reef. J. Phys. Oceanogr., 43, 1356-1379, https://doi.org/ 10.1175/JPO-D-12-0164.1.

—_ J. S. Rogers, D. Koweek, and R. B. Dunbar, 2015: Frictional wave dissipation on a remarkably rough reef. Geophys. Res. Lett., 42, 4063-4071, https://doi.org/10.1002/ 2015 GL063804.

Nezu, I., and H. Nakagawa, 1993: Turbulence in Open-Channel Flows. A. A. Balkema, 281 pp.

Péquignet, A.-C., J. M. Becker, M. A. Merrifield, and S. J. Boc, 2011: The dissipation of wind wave energy across a fringing reef at Ipan, Guam. Coral Reefs, 30 (Suppl.), 71-82, https:// doi.org/10.1007/s00338-011-0719-5.

Roberts, H. H., S. P. Murray, and J. H. Suhayda, 1975: Physical processes in a fringing reef system. J. Mar. Res., 33, 233260.

Rosman, J. H., and J. L. Hench, 2011: A framework for understanding drag parameterizations for coral reefs. J. Geophys. Res., 116, C08025, https://doi.org/10.1029/2010JC006892.

Symonds, G., K. P. Black, and I. R. Young, 1995: Wave-driven flow over shallow reefs. J. Geophys. Res., 100, 2639-2648, https:// doi.org/10.1029/94JC02736. 
Taebi, S., R. J. Lowe, C. B. Pattiaratchi, G. N. Ivey, G. Symonds, and R. Brinkman, 2011: Nearshore circulation in a tropical fringing reef system. J. Geophys. Res., 116, C02016, https:// doi.org/10.1029/2010JC006439.

Trowbridge, J., and S. J. Lentz, 2018: The bottom boundary layer. Annu. Rev. Mar. Sci., 10, 397-410, https://doi.org/10.1146/ annurev-marine-121916-063351.

Vetter, O., J. M. Becker, M. A. Merrifield, A.-C. Pequignet, J. Aucan, S. J. Boc, and C. E. Pollock, 2010: Wave setup over a
Pacific Island fringing reef. J. Geophys. Res., 115, C12066, https://doi.org/10.1029/2010JC006455.

Wright, D. G., and K. R. Thompson, 1983: Time-averaged forms of the nonlinear stress law. J. Phys. Oceanogr., 13 341-346, https://doi.org/10.1175/1520-0485(1983)013<0341: TAFOTN $>2.0 . \mathrm{CO} ; 2$.

Young, I. R., 1989: Wave transformations on coral reefs. J. Geophys. Res., 94, 9979-9989, https://doi.org/10.1029/ JC094iC07p09779. 